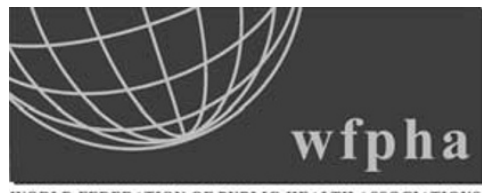

\title{
WFPHA: World Federation of Public Health Associations
}

\author{
www.wfpha.org
}

Journal of Public Health Policy (2007) 28, 136-150.

doi:10.1057/palgrave.jphp.3200117

\section{THE FEDERATION'S PAGES}

Editorial: Knowledge Management for Public Health (KM4PH):

Global WHO initiative to strengthen public health workforce worldwide

Strengthening Health Systems Through Strengthening Health Workforce Worldwide

Human resources for health $(\mathrm{HRH})$ are increasingly recognized as a crucial element in improving health systems and health services, and attaining the Millennium Development Goals (MDGs). Insufficiencies in the health workforce are becoming a major constraint in achieving the MDGs in many developing countries. Furthermore, it is widely recognized that traditional methods of educational delivery are inadequate to produce the health workforce needed in these countries.

Strategies to improve the performance of the health workforce must initially focus on existing staff because of the time lag in training new health workers. Substantial improvements in the availability, competence, responsiveness, and productivity of the workforce can be rapidly achieved through an array of low-cost and practical instruments. A strong human infrastructure is fundamental to closing today's gap between health promise and health reality and anticipating the health challenges of the 21st century (1).

\section{Public Health of the 21st Century: Knowledge Management and} Capacity Building

This is a challenging time for global public health. The HIV/AIDS pandemic, avian flu and other health crises arising from globalization 
pose new threats, which demand concerted global responses. At the same time, the worldwide public health workforce is under great stress.

To meet these challenges, it is essential to strengthen the global public health community and to facilitate strategic change using the potential of information and communication technology (ICT). This will support knowledge management (KM) and sharing for the effective translation of knowledge (research and experience) into practice, dissemination, and scaling-up of successful experiences, as well as better problem-solving and improved ability to lead and manage change.

An intersectoral global public health community supported by ICT can better assure the health of communities and improve the performance of health systems by getting the right knowledge to the right people, such as policy makers, health systems managers, public health practitioners and to the general public, at the right time and in the right form. Incorporating $\mathrm{KM}$ principles of learning, knowledge sharing and knowledge translation into the work environment of public health organizations is a seed for change. It means changing ways of working and strengthening institutional capacities through leadership and training. It is very important for public health capacity building that public health workers and community health workers are explicitly mentioned in the resolution WHA59.23 on "Rapid scaling up of health workforce production", adopted by the Fiftyninth World Health Assembly (WHA59) on 27 May 2006 (2).

The development of the Knowledge Management for Public Health (KM4PH) program was initially discussed and recommended by the Informal consultation on the global network and database for public health partners in December 2005 and further developed by the KM4PH core advisory group in close collaboration with the World Federation of Public Health Associations (WFPHA). This proposal was further discussed with the WFPHA Executive Board as well as at the 40th Annual Meeting of the WFPHA on 20 August 2006 in Rio de Janeiro, Brazil, and was accepted to become an integral part of the WFPHA strategic plan.

$\mathrm{KM} 4 \mathrm{PH}$ initiative responds in a direct manner to resolution WHA59.23, which requests the Director-General of the World Health Organization to encourage and support WHO Member States to engage in development of health-workforce planning teams and the use of innovative approaches to teaching in developing countries with state-of-the-art teaching materials and continuing education through the innovative use of ICT.

$\mathrm{KM} 4 \mathrm{PH}$ network and its activities in WHO Member States also support the Global Health Workforce Alliance (GHWA), aim to achieve a rapid 
increase in the number of qualified health workers in countries experiencing shortages through partnerships between industrialized and developing countries.

Creating and developing a global knowledge sharing network for public health through close partnership with the professional public health associations, schools, institutes, and others working in the field of public health will assist in bridging know-do gap in public health by:

- leveraging the experiential public health knowledge,

- leveraging the use of ICTs for public health workforce capacity building, and

- translating knowledge into the policy making and public health practice.

\section{Way Forward}

KM team at the World Health Organization coordinates, with the World Federation of Public Health Associations and with the International Association on National Public Health Institutes, the facilitation of a global knowledge sharing network for public health, supported by a global database of public health expertise, on-line communication platforms, and other knowledge resources including the Health InterNetwork Access to Research Initiative (HINARI), the Global Health Library (GHL) and the eGranary digital library.

Our joint vision is that by the year 2009, at the 12th World Congress on Public Health, Istanbul, Turkey, the global database of public health expertise will be fully validated with accredited data searchable in the public domain. Core public health functions/services/competencies/skills and their minimal requirements for national health systems will be established for all Member States including countries in HRH crisis. This will be seen as an essential element in public health preparedness for health emergencies. By 2010, KM approaches will become an integral part of core public health curricula and by 2015 , an integral part of public health practice.

Public health professionals will take full advantage of their accumulated knowledge, using both explicit and tacit information, and ensure that public health interventions are strategically and effectively delivered. Global public health will become a learning community significantly enhancing health outcomes and global health equity and transforming 
public health practice. This will provide an example of good practice and responsible global citizenship to other branches of health and society.

Knowledge for health will become available not only to policy makers and health professionals but also to villages and individuals using a combination of on-line resources where available and affordable, and other means such as the distribution of knowledge resources on hard drives such as eGranary digital library and access through mobile phones and PDAs. Such resources will be used alongside books and school teaching aids, radio and television to improve health literacy and health in all Member States.

For more information about the KM4PH program visit: http:// www.who.int/km4ph and http://www.wfpha.org.

\section{REFERENCES}

1. The World Health Report 2006: Working together for health. Geneva, World Health Organization, 2006.

2. Rapid scaling up of health workforce production: Resolution WHA59.23, 59th World Health Assembly, 2006.

\section{Contact:}

Alena Petrakova, MD, PhD

KM4PH Project Manager

Knowledge Management and Sharing

World Health Organization, Geneva, Switzerland

E-mail: petrakovaa@who.int

\section{Special Reports}

Bangladesh Health Watch: A Civil Society Initiative to Monitor Progress in Achieving Good Health for All Citizens

In Bangladesh, civil society has played an important role in setting agendas and monitoring the nation's progress. Civil society networks are active in several sectors such as: education (CAMPE), environment (BAPA), and governance (Transparency International). In the health sector, civil society has done policy advocacy in the 1980s and 1990s. Community level "health watch" groups exist in several regions of the country supported by NGOs. Various networks have been established at 
the national level. Drawing on such ongoing initiatives and building on past experience, a number of individuals representing different sections of civil society met several times over the past few months to explore the possibility of initiating a process of institutionalizing a monitoring system for health in Bangladesh. They are now in a position to propose the setting up of a National Health Watch.

The Health Watch: In order to monitor Bangladesh's progress towards the achievement of the goal of good health for all citizens including the realization of the Millennium Development Goals, this civil society initiative will publish on a yearly basis, a report on the state of health in Bangladesh. Based on secondary/primary data, as the situation may necessitate, each year's report will deal with different issues related to citizen's health. The Watch group will also use other monitoring and advocacy measures such as conferences, meetings, press briefings, and media reports to engage the policy makers as well as program implementers in the public, private and NGO sectors along with other actors such as academia, media and donors with the ultimate goal of realizing good health for all.

Watch Report 2006: The first report, to be published in October 2006, will deal with the issue of health equity. Much of the data for taking a critical look at inequities in health are already available and will thus be used in the first report.

An Advisory Board consisting of eminent persons in the country has been nominated to provide guidance to the Watch. Dr Rounaq Jahan, Director, Research Initiatives Bangladesh (RIB) and Adjunct Professor, Columbia University, USA is the Convener.

\section{Contact:}

Professor Rounaq Jahan

Columbia University, USA

E-mail: rj15@columbia.edu

\section{WFPHA Resolutions Revisited}

In this new section, we comment on some of the most relevant WFPHA resolutions with regard to new developments and additional considerations. The complete text of the respective resolutions can be found at the WFPHA website: http://www.wfpha.org/pg_about_policy.htm. 


\title{
Global Trade And Public Health
}

\author{
(abbreviated version)
}

The WFPHA has declared its interest in taking a leadership role in drawing attention to international and national disparities in health that are a consequence of global economic change, to the new health challenges posed by globalization and by the failure of the international community to implement effective interventions. In May 2007, the World Health Assembly of the World Health Organization (WHO) will report its progress on two resolutions, one calling for concerted attention to the implications of global trade agreements for public health, and the second calling for a global reassessment of research and development for pharmaceuticals. In United States, the American Public Health Association (APHA) is supporting a campaign to appoint public health representatives to trade policy advisory committees. At the Rio meeting in 2006, the Executive Committee of the WFPHA discussed how national public health associations and the Federation itself can take effective action.

This article updates and summarizes two key policy statements on global trade and public health adopted by the WFPHA in 2003 and 2004: International Trade Agreements: Priorities for Health, WFPHA Position Paper, 2003, initiated by APHA; and Health and International Trade Agreements, proposed by the Public Health Association of Australia (PHAA), revised by Professor Theo Abelin and the Policy Committee of the WFPHA, April 19, 2004. It also draws on a third resolution: Public Health and Globalization, Presented to UK Public Health Associations Policy Committee, 2001, Proposed by the WFPHA Resolutions Committee, WFPHA 35th Annual Meeting May 14, 2001.

The promise and peril of globalization for health and well-being

Good health in all parts of the population is a moral good in itself, as well as a prerequisite for economic growth and sustainable development. Public health decision-making should be able to ensure that the entire population is equitably reached by effective public health measures and that everyone has access to essential health services and medicines. No population groups, families or individuals should be excluded from access because of inability to pay or any other characteristics.

International trade agreements, and national laws passed to conform with trade agreements, are intended to "liberalize" trade. By reducing tariffs on goods and services, and by reducing government regulations 
referred to as "non-tariff" barriers, these measures promise to provide more goods and services at lower prices to consumers. However, to the extent that these agreements limit governments' legitimate authority to protect the public from market failures, they often heighten the risk of harm. This is particularly the case when they are designed without participation by public health and civil society, and when they lack formal regulations and implementing rules in favor of public health.

Trade agreements are enforced through a dispute settlement process, which can impose financial penalties or trade sanctions on the losing country. In the case of a conflict between trade rules and the provisions of health-oriented agreements, such as the Framework Convention on Tobacco Control and Multilateral Environmental Agreements, it is not clear which would prevail.

\section{Who decides?}

Generally, the responsibility for setting trade policy and for negotiating trade agreements resides with the executive branch of government. Trade and finance ministers take the leading role. While there is great variability among countries, health ministers, public health advocates, and civil society generally play a secondary role, and in some cases are not consulted at all.

Trading in vital human services, challenging public health protections, GATS

The General Agreement on Trade in Services (GATS) is a WTO agreement that sets the rules for how services will be traded globally by private transnational corporations. Covered services include vital human services such as health care, water and sanitation, education, libraries and energy, as well as finance, banking, telecommunications, distribution services, and construction, all of which have implications for health.

The goal of GATS is to "progressively liberalize" all services. This means reducing and eliminating the barriers to international trade in services, which include both tariffs, and "non-tariff barriers to trade." Nontariff barriers consist of a web of local, state, and national regulations on rights, the quality of services, professional licensing, and privacy. These may protect safety, the environment, working conditions, or health, and can include public subsidies for vital human services such as health care 
and water. The health-related laws and regulations at stake include clinician licensing; controls on the distribution of tobacco, alcohol, and firearms; data privacy rules (e.g., patient health and billing information); requirements to allocate medical equipment and services based on need; health insurance regulations; environmental protections; occupational safety and health regulations; protections from hazardous materials; restraints on corporate ownership of hospitals; the ability of governments to maintain viable services in water and sanitation; and the safety of medical equipment.

Both private and public services are subject to GATS: GATS states that it excludes public services "provided in the exercise of government authority" if they are "supplied neither on a commercial basis nor in competition with one or more service suppliers." Since some aspects of public services are frequently also provided in the private sector, or at least have commercial relationships with private suppliers, there is doubt that many services would actually be exempt under this definition. To be protected, vital human services must be specifically and permanently excluded from international trade agreements.

\section{Health care personnel and GATS}

WTO conferences have explored how the rules might be applied to licensing requirements for nurses and other health professionals. The World Health Organization has cautioned member states to proceed slowly in committing health care services to full coverage under GATS, and there appears to be a hiatus in negotiations since the WTO deadlock in July, 2006. The European Union decided to exclude its own health, education, energy and water sectors from trade negotiations, but may still ask other countries to make commitments in these areas. However, services comprise an important and growing share of many economies, and are likely to remain a focus of talks. In addition, GATS provisions are being adopted in bilateral and regional agreements.

The migration of clinicians raises several important questions, including international agreement on standards for professional training and practice, adequate availability of trained clinicians and service providers in countries that "import" and "export" such workers, and assurance of fair working conditions (see also the WFPHA resolution on professional migration). 
Other WTO agreements with implications for health

Trade Agreements and Access to Medicines, TRIPS: Implemented in 1995, when the World Trade Agreement (WTO) was formally established, the TRIPS Agreement (Trade-Related Aspects of Intellectual Property Rights) codifies the rights that pharmaceutical companies and other patent holders enjoy internationally to market their products without competition from generic companies for about 20 years. In November 2001, during its meeting in Doha, Qatar, the WTO Ministerial Conference adopted the Doha Declaration on the TRIPS Agreement and Public Health. The Doha Declaration asserts that trade agreements should be interpreted and implemented so as to protect public health and promote access to medicines for all. It aims to ensure that trade agreements address market failures and balance protection of investor assets with a State's sovereign right to address public health needs (see also the recently updated WFPHA resolution on essential drugs (The Federation Pages, JPHP 27(3), p. 313-14, 2006).

Agreement on Technical Barriers to Trade (TBT): Reduces barriers to trade that derive from technical standards and regulations applying to the safety and quality of products; covers tobacco and alcohol control, toxic substances and waste, pharmaceuticals, biological agents, foodstuffs, and manufactured goods.

Agreement on the Application of Sanitary and Phyto-Sanitary Standards (SPS): Reduces barriers to trade that derive from governments' regulations and laws designed to protect the health of humans, animals, and plants; covers food safety provisions.

Agreement on Agriculture: Sets the terms for tariffs and subsidies on agricultural products, a significant source of contention among higher and lower income countries. Tobacco may be considered an agricultural product.

\section{Protecting All Nations' Health}

Facilitating trade among private transnational corporations is not sufficient justification for requiring nations to sacrifice their rights to protect the public's health and safety, or to dictate the standards and definitions local and national governments and regulatory bodies will use to enforce those protections. Authority and accountability for population health need to be shifted back to health organizations. A road toward empowering effective 
international health organizations has to be built to achieve universal access to vital human services.

Countries play a pivotal role in shaping the ground rules for global trade. They have an important opportunity to promote a safe and just global community with publicly accountable and sustainable health care, water, and other vital human services. The health care community's voice can make an important difference.

The WFPHA recognizes that a number of governments

- find it difficult to adequately protect population health needs within the context of international trade agreements;

- make commitments in trade liberalization negotiations before presenting the issues to their countries' political decision making bodies;

- unilaterally delegate representatives to trade negotiations whose primary interest is in trade liberalization rather than public health.

The WFPHA thus affirms that the health care community should call on national Trade Representatives, the World Health Organization, and members of national Parliaments to:

1. Embed sustainable development as a key principle engaging all aspects of public health activity globally and nationally.

2. Assess the impact of multilateral, regional and bilateral trade agreements on population health, as provided, for example, in GATS Article XIX, and assure, based on such assessment, that policy proposals do not have an adverse impact on health or create conditions that undermine health promotion, as required in article 129 of the Maastricht treaty (1992) and article 152 of the Amsterdam treaty (1997).

3. Exclude vital human services such as health and water, pharmaceutical products, and harmful substances such as tobacco and alcohol, from trade negotiations and challenge under trade rules, for all WTO countries.

4. Advocate that the principle of health before trade be applied to all trade negotiations and oppose the retraction of public health regulations and health-related international treaties as a prerequisite to trade negotiations.

5. Advocate that the WTO establish rules to ensure that minimum standards to protect public health set in WTO agreements cannot be weakened in regional and bilateral negotiations. 
6. Promote transparency and democratic accountability at all levels of trade negotiations.

7. Assure public health representation at all levels of trade policy and negotiations. Urge the WHO to fulfill its mandated role of safeguarding public health by seeking participatory status at WTO Tribunal and Appellate body hearings in order to represent the health interests of populations in countries with disputes before these bodies.

8. Support enforceable commitments to advancing population health, and to achieving universal access to health care and to safe, affordable water in all countries.

Further:

- WFPHA calls upon its member associations to be concerned with and educate themselves in the issues relating to public health and international trade.

- Member associations are encouraged to advocate in their countries for an active government policy to conduct health impact assessments as part of the background to any proposed trade agreement (whether multilateral or bilateral).

- Every effort should be made to aid member associations in lower and middle income countries to secure support enabling them to engage in these activities in their countries.

\section{REFERENCES}

1. Based on a Briefing Paper of the Center for Policy Analysis on Trade and Health, San Francisco, CA 94121 1437, www.cpath.org

2. Wallach L, Sforza M. The WTO. Five Years of Reasons to Resist Corporate Globalization. New York: Seven Stories Press; 1999.

3. Chanda R. Trade in health services. Working Paper No. 63. Commission on Macroeconomics and Health, World Health Organization, June 2001.

\section{Contact:}

\section{Ellen Shaffer}

Center for Policy Analysis on Trade and Health

San Francisco, CA 94121 1437, USA

E-mail: ershaffer@cpath.org

www.cpath.org 


\section{WFPHA News \& Notes}

\section{Minutes of The Annual Assembly of The World Federation of Public} Health Associations

Rio de Janeiro, August 20, 2006

(Abbreviated version; the full version is subject to final approval at the next assembly in 2007 and can be obtained from the secretariat in WFPHA

Washington, DC)

President Cuauhtemoc Ruiz Matus opened the meeting.

(1) Representatives from each of the member associations present at the meeting offered a brief report. Countries present include: Bangladesh, Brazil, China, Japan, Germany, Ethiopia, Turkey, Canada, Switzerland, Cuba, Mozambique, Haiti, United States, Russia, Malawi, Uganda, Spain, Burkina Faso, Congo, Chile, Costa Rica, Finland, Hungary, New Zealand, Mexico.

(2) Following the member association reports, Turkey gave a brief presentation announcing that the 2009 WFPHA Congress will take place in Istanbul, Turkey. Dates and theme are still to be determined.

(3) Reports were presented by the president and the secretariat (the written reports are published at the website of WFPHA (www.wfpha.org).

The WHO liaison officer Dr Alena Petrakova highlighted the partnership between WHO and WFPHA. She gave an overview of the Global Database for key networking.

Professor Peter Orris, USA asked the EB to construct a committee to move forward at the World Health Assembly (WHA) next year with the briefings on technical topics, similar to the ones that had been prepared and postponed during the WHA 2006.

(4) Selected reports by the chairpersons of WFPHA Committees:

(a) Theo Abelin reported that the Awards Committee considered applications for the Leavell Lecture Award and for the Institutional Award. The committee received 12 nominations from seven countries for the Leavell Award and five nominations from three countries for the Institutional Award. A question was raised about whether or not both awards could go to the same country. For this round, it was decided that both would be judged on merit and not country of origin. Paulo Buss, President of Fiocruz, was selected 
as the recipient of the Leavell Lecture Award and his organization, FIOCRUZ, received the Institutional Award.

(b) Theo Abelin reported on behalf of the Membership Committee chair who was unable to attend the meeting. Four applications for membership were received from Algeria, Serbia, Burkina Faso, and Vietnam. Serbia and Burkina Faso were accepted as full members. Vietnam's application was also supported, but the new applicant first needs to contact Vietnam's other member association as WFPHA encouraged the two to form an umbrella organization. Algeria's application requires further research, as a question exists as to whether the membership of the association is truly crosscutting or merely medical. Further research into the matter is being conducted and the decision on membership has been postponed to a later date. The Assembly approved the recommendations of the Membership Committee by a voice vote.

(c) Ulrich Laaser, chair of the Health Policy Committee, reported that the Journal of Public Health Policy has pages allocated to WFPHA. He noted that the policy committee should focus on looking at legislation for public health in order to develop a common strategy. Use of the journal's pages can be an opportunity for WFPHA to highlight the impact of WFPHA's activities on public policy. He noted that the Policy committee should revisit WFPHA's resolutions and the process of how resolutions get passed and become official. The Federation needs to monitor its resolutions. Steps concerning what to do after the adoption of a resolution, as well as considering what future steps should be taken towards implementation need to be established. One suggestion was that the association proposing the resolution be charged with coordinating the implementation. Some objections were raised concerning this point and it was agreed that implementation strategies should be explored. Members asked the Secretary General to send out a packet including hardcopies all approved resolutions to member associations for their review. Due to Internet accessibility issues, members require hardcopies of communications. Internet is not always reliable, affordable or convenient for many member associations. The Policy Committee reported also that the word changes submitted to it regarding the HIV Resolution had been agreed upon and so that the resolution passed by the Assembly with a voice vote. 
(5) Selected reports on WFPHA Projects:

(a) Human Resources for Health: Human Resources for Health is an essential part of the MDGs. PAHO reviewed this goal in its region and discovered that the region is one of the weakest in terms of meeting this MDG. WFPHA can play a large role in reaching this MDG. In Brighton, WFPHA decided to admit Schools of Public Health as members because these are the places where future health workers are being trained. It was decided that a definition of "who is working in public health" should be created and explored.

(b) Tobacco Control: This project is developed within the Framework Convention on Tobacco Control (FCTC). In 2004, the Federation developed a resolution to initiate joint programming within the international umbrella of healthcare professionals. Healthcare professionals have not always taken interest in policy level issues related to tobacco control. The Program works with medical associations in different countries to help them understand the policy level issues and to understand the role of the tobacco industry.

(c) International Hand-washing Campaign: The Colgate Palmolive Company is working in collaboration with WFPHA to promote and to examine hand-washing practices. Initiatives are taking place in Mozambique and South Africa. These countries are asked to provide the Secretariat with full reports on the status of the project in order to provide more support in the future. Mozambique reports that the project had been initiated and the implementation phase was beginning in schools, but needed more input from the local company.

(6) Elections: The General Assembly approved the Nomination Committees slate by voice vote to confirm the new Executive Board and to elect Paulo Buss, Brazil as the new Vice President/President-Elect.

Meeting adjourned with a reception and film screening following.

\section{New Template for the Annual Reports of the Publc Health Associations}

The Executive Board of WFPHA discussed and decided in Rio de Janeiro that starting from the next Annual Assembly (Geneva 2007) member associations should report according to a common template which is in a first version drafted below. The Chair of the Health Policy Committee was 
charged to summarize these reports and present a general report on the development of the member organizations at the Annual Assembly each year. The reports should be structured as follows:

\begin{tabular}{|c|c|}
\hline \multicolumn{2}{|c|}{ ANNUAL REPORT OF MEMBER ASSOCIATIONS OF WFPHA } \\
\hline Period covered: & $2006 / 2007 \ldots \ldots \ldots$ \\
\hline $\begin{array}{l}\text { Full legal name of the } \\
\text { Association incl. official } \\
\text { abbreviation: }\end{array}$ & \\
\hline $\begin{array}{l}\text { Full contact details of the } \\
\text { head office(incl. TEL, FAX, } \\
\text { E-MAIL, URL): }\end{array}$ & \\
\hline $\begin{array}{l}\text { Full name and titles of } \\
\text { president: }\end{array}$ & \\
\hline $\begin{array}{l}\text { Full name and titles of } \\
\text { executive director/general } \\
\text { secretary: }\end{array}$ & \\
\hline $\begin{array}{l}\text { Membership (number at the } \\
\text { end of the last year): }\end{array}$ & \\
\hline $\begin{array}{l}\text { List of publications during } \\
\text { the reporting period (full } \\
\text { references incl. ISBN, ISSN): }\end{array}$ & \\
\hline $\begin{array}{l}\text { List of conferences and } \\
\text { public meetings during the } \\
\text { reporting period (dates, } \\
\text { locations, themes, } \\
\text { at tendance): }\end{array}$ & \\
\hline $\begin{array}{l}\text { List of ongoing Research \& } \\
\text { Development projects during } \\
\text { the reporting period (Topics, } \\
\text { donors, names of principal } \\
\text { investigators incl. their } \\
\text { contact details esp. e-mail): }\end{array}$ & \\
\hline $\begin{array}{l}\text { List of activities } \\
\text { prepared/planned for the } \\
\text { next reporting period: }\end{array}$ & \\
\hline $\begin{array}{l}\text { Expectations and proposals } \\
\text { regarding the WFPHA: }\end{array}$ & \\
\hline Additional comments: & \\
\hline
\end{tabular}

